\title{
DDS Profile: Maria T. Abreu, MD
}

\author{
Maria T. Abreu ${ }^{1}$
}

Published online: 18 October 2019

(c) Springer Science+Business Media, LLC, part of Springer Nature 2019

So, what's my story, and why did I agree to write this piece? I will begin with the conclusion that if I could do it, anyone can. We are so lucky to be gastroenterologists, which I believe is the "coolest" thing anyone can do in medicine, with endless opportunities. My specific academic path has been as a physician-scientist. I really always knew that I wanted to stay in academics. There are so many great reasons to be in academics-more on that later.

Before getting too far into the story of my academic life, the first disclaimer is that everything I have accomplished is thanks to my wonderful parents. They met in Miami after their island of Cuba was taken over by Fidel Castro. Dad was in the Bay of Pigs invasion. Much of who I am relates to this very strong culture-passionate, opinionated, and resilient (and a love of dancing). My parents set the example for hard work, delayed gratification, and education as a means to a better life. No one in the family was a doctor, but my desire to become one was nourished in every possible way, including Cuban coffee at midnight if I was studying for an examination. The first time I left home was to begin my residency in Boston. Until that time, I was spoiled by my parents, grandmothers, and aunts.

Although I was born in New Jersey, Miami is home. I did a 6-year medical program at the University of Miami in which I combined 2 years of college with medical school. It was during medical school that David Carr-Locke (now at Weill Cornell Medicine) and MichaeI Wolfe (now retired from MetroHealth in Cleveland) served as my inspirations to do gastroenterology. I did my internal medicine residency at the Brigham and Women's Hospital in Boston and shorttracked into a gastroenterology fellowship at the University of California, Los Angeles (UCLA). Medicine at the Brigham was superb (and still is). I had the most amazing

Maria T. Abreu

MAbreu1@med.miami.edu

1 Division of Gastroenterology, Crohn's and Colitis Center, University of Miami Miller School of Medicine, 1011 NW 15th Street, Gautier, Suite 510 (D-149), Miami, FL 33136, USA co-residents. Life was lived intensely, and I am grateful that work-hour restrictions were not in full force at that time.

During my gastroenterology fellowship, several people were particularly important in shaping my career. Fred Weinstein taught me the most about general gastroenterology, and his quips are still in my brain-and are passed on to my current fellows. John Walsh, who described most of the physiology of gastrin, shepherded me through various laboratories to help me find my eventual niche and involved me in the American Gastroenterological Association (AGA). He also invited me to a barbecue at his house at which I met a newly recruited attending, Paul Martin, with whom I just celebrated 25 years of marriage.

Even as a full professor now, I still identify my mentor as Stephan Targan at Cedars-Sinai. It was his passion and energy that attracted me to inflammatory bowel disease (IBD) research and clinical care. I have always wanted to grow up to be like him. Although I could never hope to achieve what Steph has in his remarkable career, I have had a basic science laboratory and a translational research focus that is based on the model that I grew up with at CedarsSinai. In 2018, I was accepted into the Association of American Physicians (AAP); I was so proud to be accepted and have a picture of Steph and me on my desk at this happy occasion.

After 13 years in Los Angeles, I spent almost 4 years at Mount Sinai Medical Center in New York. I was recruited to Mount Sinai by Lloyd Mayer to lead their IBD program. His untimely death in 2013 left a void in many lives including those of young scientists who would have benefitted from his inspiration and support. The years at Mount Sinai were intense, exciting, and fulfilling. I made lifelong friends and learned from luminaries in IBD, all of whom had different opinions about absolutely everything.

Much to Lloyd's chagrin, I was recruited to go home to the University of Miami School of Medicine, where I was Chief of the Division of Gastroenterology for almost 9 years. It was a time of rapid growth in the gastroenterology division, and I am proud of the faculty I recruited during that time. With my colleagues, we built a Crohn's and Colitis 
Center, a visible expression of the care we offer our IBD patients. What makes it a true center is not the physical place, but the great people who work there, including our nurses, research coordinators, dietician, and social worker. They always make me proud!

Professionally, seeing patients and doing science make me happy. Since I could not increase the number of hours in the day, I made the difficult decision to step down as Chief. Selfishly, I wanted the opportunity to do other things that I enjoy. At this stage of my career, I want to make sure the pipeline of physician-scientists is well cared for and that all trainees and faculty have the opportunity to reach their full potential. Oriana Damas at the University of Miami represents the next generation of IBD investigators. She has recently been awarded a K23 career development award from the National Institutes of Health (NIH) to study the genetics of IBD and dietary factors leading to a rising rate of IBD in Hispanic immigrants. To that end, I am excited to be a mentor in an AGA-NIH-sponsored program led by Byron Cryer called the AGA FORWARD (Fostering Opportunities Resulting in Workforce and Research Diversity) program. I was assigned a terrific mentee, Yelina Alvarez-an already accomplished $\mathrm{MD} / \mathrm{PhD}$ gastroenterology fellow at the Perelman School of Medicine, University of Pennsylvania. Although she came from Cuba as a teenager, she was able to attend college, medical school, residency, and now fellowship in top US institutions. She does not need my help, but I am delighted to witness her successes up close. With that backdrop, one of my most cherished awards was from the American College of Gastroenterology - the Minority Digestive Health Care Award. The award was given to me to recognize my promoting the career of minority trainees and faculty and promoting minority health research.

There are perks of academia. I still become excited about going to Digestive Disease Week (DDW). Part of the excitement is the feeling that I am not only an attendee, but also an active participant. I had an opportunity to play a role in planning DDW as Chair of the AGA Council. The best part of DDW is when one of my trainees is presenting; I become emotional every time a trainee of mine presents. It is also wonderful to see old friends and make new ones.

None of my professional activities would be meaningful if I did not have a wonderful family - a husband who is my best adviser, and two kids who just graduated college and have tolerated a busy mother. My parents are still an everpresent part of my life. I am blessed with terrific friends: my Miami "peeps" as well as great friends from the world of IBD. We try to enjoy every opportunity to get together and always have fun when we are at meetings (but please don't let our secret out!). In my spare time, I have developed a passion for running and participate in triathlons. I am not good at any of the three sports and am always on a never-ending quest to improve. Life is an endurance sport, and my choice to be a gastroenterologist has made it a very rich one.

Publisher's Note Springer Nature remains neutral with regard to jurisdictional claims in published maps and institutional affiliations. 